\title{
Mutations in Exon 3 of the Lipoprotein Lipase Gene Segregating in a Family with Hypertriglyceridemia, Pancreatitis, and Non-insulin-dependent Diabetes
}

\author{
Dana E. Wilson, ${ }^{*}$ Akira Hata, ${ }^{\ddagger}$ Linda K. Kwong, * Arunth Lingam, ${ }^{\star}$ Joan Shuhua, ${ }^{\ddagger}$ David N. Ridinger, ${ }^{*}$ Chris Yeager, \\ Konrad C. Kaltenborn, * Per-Henrik Iverius, * and Jean-Marc Lalouel ${ }^{\star}$ \\ ${ }^{\ddagger}$ Howard Hughes Medical Institute and Department of Human Genetics, University of Utah, Salt Lake City, Utah 84132; ${ }^{*}$ Veterans \\ Affairs Medical Center, Salt Lake City, Utah 84148; and *Division of Endocrinology and Metabolism, Department of Internal Medicine, \\ University of Utah Health Sciences Center, Salt Lake City, Utah 84132
}

\begin{abstract}
A proband with chylomicronemia, pancreatitis, and non-insulin-dependent diabetes (NIDDM) bears two different mutations in exon 3 of the lipoprotein lipase (LPL) gene: a missense mutation, ${ }^{75} \mathrm{Arg} \rightarrow$ Ser, inherited through the paternal line and a truncation, ${ }^{73} \mathrm{Tyr} \rightarrow$ Ter, through the maternal line. NIDDM appeared to be independently segregating. The $\mathrm{R75S}$ mutant was studied in extracts and media from transfected COS-1 cells. Detectable amounts of catalytically competent $R 75 S$ LPL suggested destabilization of the active homodimer as with exon 5 mutants (Hata et al. 1992. J. Biol. Chem. 267: 2013220139). Hydrolysis of a short-chain fatty acid ester indicated that R75S does not directly affect activation of LPL by apoCII. Subjects with NIDDM and wild-type LPL, and nondiabetic middle-aged carriers of the ${ }^{73} \mathrm{Tyr} \rightarrow$ Ter truncation had moderate hypertriglyceridemia $(260-521 \mathrm{mg} / \mathrm{dl})$ and reduced high density lipoprotein cholesterol. A maternal aunt with NIDDM carried the truncation. Her phenotype (triglycerides of 5,300 $\mathrm{mg} / \mathrm{dl}$, eruptive xanthomatosis, and recurrent pancreatitis) was as severe as that in homozygotes or compound heterozygotes. We conclude: ( $a$ ) diabetic carriers of dysfunctional LPL alleles are at risk for severe lipemia; and $(b)$ the physiologic defects in NIDDM may be additive or synergistic with heterozygous LPL deficiency. (J. Clin. Invest. 1993. 92:203-211.) Key words: chylomicrons - familial lipoprotein lipase deficiency • lipoprotein lipase • non-insulin-dependent diabetes mellitus • pancreas
\end{abstract}

\section{Introduction}

Lipoprotein lipase (LPL) ${ }^{1}$ catalyzes the hydrolysis of triacylglycerols in the cores of chylomicrons and VLDL. Knowledge of the complementary $(1,2)$ and genomic sequences $(3,4)$ of the LPL gene has enabled investigation of naturally occurring and artificially created mutations. Such studies can provide information about the function of LPL at the molecular level,

Dr. Hata's present address is Department of Biochemistry, Nagoya City University Medical School, Mizuho-ku Nagoya 467, Japan.

Address reprint requests to Dr. Wilson, Endocrinology Section (111E), VA Medical Center, 500 Foothill Boulevard, Salt Lake City, UT 84124 .

Received for publication 16 December 1992 and in revised form 11 February 1993.

1. Abbreviations used in this paper: $\mathrm{FCH}$, familial combined hyperlipidemia; LPL, lipoprotein lipase; NIDDM, non-insulin-dependent diabetes mellitus; PNPB, $p$-nitrophenyl butyrate.

The Journal of Clinical Investigation, Inc.

Volume 92, July 1993, 203-211 and how genetic variation affects phenotype. Roughly two dozen mutations have now been identified in propositi with LPL deficiency (5). Rearrangements $(6,7)$, splice site $(8,9)$, and nonsense (10-13) mutations (stop codons or frameshifts in exons 3,5 , or 6 ) result in enzyme deficiency through mRNA instability or the synthesis of truncated, catalytically inactive proteins.

Most reported index cases, however, have been homozygotes or compound heterozygotes for missense mutations that cluster in exons 4-6 and encode residues in the $\mathrm{NH}_{2}$-terminal folding domain responsible for catalysis $(5,14)$. Most of these mutations fail to involve residues participating directly in catalysis. Only two (D156N and D156G $[15,16])^{2}$ involve the catalytic triad $\left({ }^{132} \mathrm{Ser},{ }^{156} \mathrm{Asp},{ }^{241} \mathrm{His}\right)$ itself. The majority of missense mutations must therefore affect enzyme function by indirect mechanisms $(5,17,18)$.

Type I hyperlipoproteinemia (familial hyperchylomicronemia) results either from LPL deficiency or from the absence of LPL cofactor, apolipoprotein C-II (apoC-II) (19). Index cases typically present in infancy with intolerance to dietary fat, abdominal pain with or without pancreatitis, eruptive xanthomas, and severe hypertriglyceridemia with fasting chylomicronemia. Heterozygous carriers manifest age-dependent familial hypertriglyceridemia typically with reduced LDL and HDL cholesterol concentrations (type IV hyperlipoproteinemia) (5, 20). However, increased LDL cholesterol has also been reported in obligate heterozygotes, consistent with familial combined hyperlipidemia (FCH). It was therefore suggested that LPL deficiency is involved in the pathogenesis of FCH (21).

We recently described in vitro studies of exon 5 mutants known to result in clinical LPL deficiency (A176T, G188E, G195E, and S244T) (18). Wild-type and mutant sequences were expressed in vitro in COS-1 cells and heparin binding was assessed by high-resolution affinity chromatography. For all of these mutants a catalytically inactive protein with reduced affinity for heparin was detected in the culture media by a specific ELISA. Small amounts of enzymatically active LPL with an affinity for heparin identical to that of wild-type enzyme were recovered from cell lysates from one mutant, G188E ( 18 , 22 ). Other evidence indicates that these mutations encode a potentially active but intrinsically unstable LPL homodimer, thus leading to LPL deficiency (18).

A subset of susceptible patients develops severe hypertriglyceridemia in the context of poorly controlled NIDDM. Such individuals are believed to possess an independently inherited disorder of lipid metabolism (23). On the assumption of Hardy-Weinberg equilibrium and a rough estimate of the prev-

2. The letter-number-letter nomenclature for missense mutations indicates the wild-type residue by its single-letter code, the residue position in the mature enzyme, and the substituted residue, respectively. 
alence of homozygous LPL deficiency, we proposed that heterozygous LPL deficiency in combination with abnormalities in lipoprotein metabolism resulting from diabetes accounts for instances of diabetic lipemia (24). Heretofore there has been no direct support for this hypothesis.

We now describe two previously unreported mutations in the LPL gene in siblings with type I hyperlipoproteinemia. One has overt non-insulin-dependent diabetes (NIDDM) and the other has mild diabetes of recent onset. These brothers proved to be compound heterozygotes for a nonsense (Y73Ter) and a missense (R75S) mutation, both in exon 3. The R75S mutant enzyme was transiently expressed in COS- 1 cells and several of its biochemical properties were investigated. Lipoprotein phenotypes were examined in the extended pedigree in subjects with NIDDM homozygous for wild-type LPL, in carriers of the LPL mutations without NIDDM, and in a subject with NIDDM who carried the Y73Ter mutation.

\section{Methods}

Subjects. The proband in kindred 2062, a 43-yr-old male of German and English-Irish ancestry, was the offspring of a nonconsanguineous union (Fig. 1). Lipemia was noted during infancy, and the subject recalled recurrent episodes of abdominal pain precipitated by dietary fat throughout childhood. As an adult, overt pancreatitis was documented on at least one occasion. Although the proband had never had xanthomas, he had been told that his spleen and possibly his liver were enlarged. During periods of unrestricted fat intake plasma triglycerides were as high as $\sim 10,000 \mathrm{mg} / \mathrm{dl}(113 \mathrm{mM})$. His plasma, after standing overnight at refrigerator temperature, was described: "the upper $80 \%$ looked like whole milk, and the bottom was hazy yellow." With dietary fat restriction plasma triglycerides fell to $\sim 1,500 \mathrm{mg} / \mathrm{dl}(17 \mathrm{mM})$. Although he was lean ( $178 \mathrm{~cm}$ tall; $74 \mathrm{~kg}$; body mass index $23.4 \mathrm{~kg} / \mathrm{m}^{2}$ ) the proband developed NIDDM at age 42 and was begun on oral sulfonylurea treatment with a subsequent glycated hemoglobin concentration of $5.1 \%$ (normal range 5.3-8.3\%). Three offspring, two sons and a daughter, were ostensibly healthy. The proband had divorced and remarried and blood from the children's biological mother was obtained by mail. Plasma lipoprotein analyses were performed accord- ing to Lipid Research Clinics guidelines on venous blood samples collected after subjects had fasted 12-15 h. The 11-yr-old daughter's lipids were resampled after abnormalities were found initially; no changes in dietary habits were made in the interim. These studies were conducted with informed consent under protocols approved by the Institutional Review Board at the University of Utah.

Lipase activity in postheparin plasma, culture media, and fast protein liquid chromatography column fractions was measured as described in detail elsewhere $(10,25)$. For plasma samples, LPL and hepatic lipase activities were calculated as the fractions of total lipolytic activity that were and were not inhibited, respectively, by a polyclonal antibody to LPL. Lipoprotein lipase mass was determined by a competitive enzyme-linked immunosorbent assay using a monoclonal antibody to bovine LPL (5D2) against standards of purified bovine LPL (10). Results of pre- and postheparin mass and activity were compared to previously published values given for normal individuals $(21,26)$. Analytical heparin-Superose chromatography was also performed as described previously (10).

Hydrolysis of the short-chain fatty acid ester ( $p$-nitrophenyl butyrate, PNPB) was assayed with minor modifications of published methods (27-29). Working PNPB substrate (Sigma Chemical Co., St. Louis, $\mathrm{MO})(1.0 \mathrm{mM})$ was prepared by the addition of Triton X-100 $(150 \mathrm{mM})$ to the desired amount of PNPB $(50 \mathrm{mM})$ in acetonitrile (Mallinckrodt Special Chemicals Co., Paris, KY) and assay buffer was added dropwise with stirring (27). The final Triton concentration, 0.25 $\mathrm{mM}$, was taken from a published estimate of the critical micellar concentration, $0.20 \pm 0.05 \mathrm{mM}(29)$. Final concentrations in the assay were as follows: sodium phosphate $0.05 \mathrm{M}, \mathrm{NaCl} 0.1 \mathrm{M}$, glycerol $10.0 \%$ (wt/vol); heparin $10.0 \mu \mathrm{g} / \mathrm{ml}$, Triton X-100 $0.25 \mathrm{mM}$, acetonitrile ( vol/vol) $2.0 \%$, and PNPB $800 \mu \mathrm{M}$. The absorption maximum of $p$-nitrophenol in the assay buffer at $\mathrm{pH} 7.3$ was $401.5 \mathrm{~nm}$ and its molar absorption coefficient was determined to be 14,510 , close to the published value of $14,780(28)$. The sensitivity of the assay was limited by nonenzymatic hydrolysis of PNPB in aqueous solution, and neither the acetate nor propionate ester showed slower spontaneous hydrolysis. The ratio of enzymatic-to-spontaneous hydrolysis was favored at lower temperatures and so assays were routinely performed at $25^{\circ} \mathrm{C}$.

PNPB assays were carried out in $600 \mu 1$ of total volume in disposable polystyrene microcuvettes monitored continuously in a temperature-controlled model DU-70 spectrophotometer (Beckman Instruments, Inc., Palo Alto, CA). Reactions were begun by the addition of

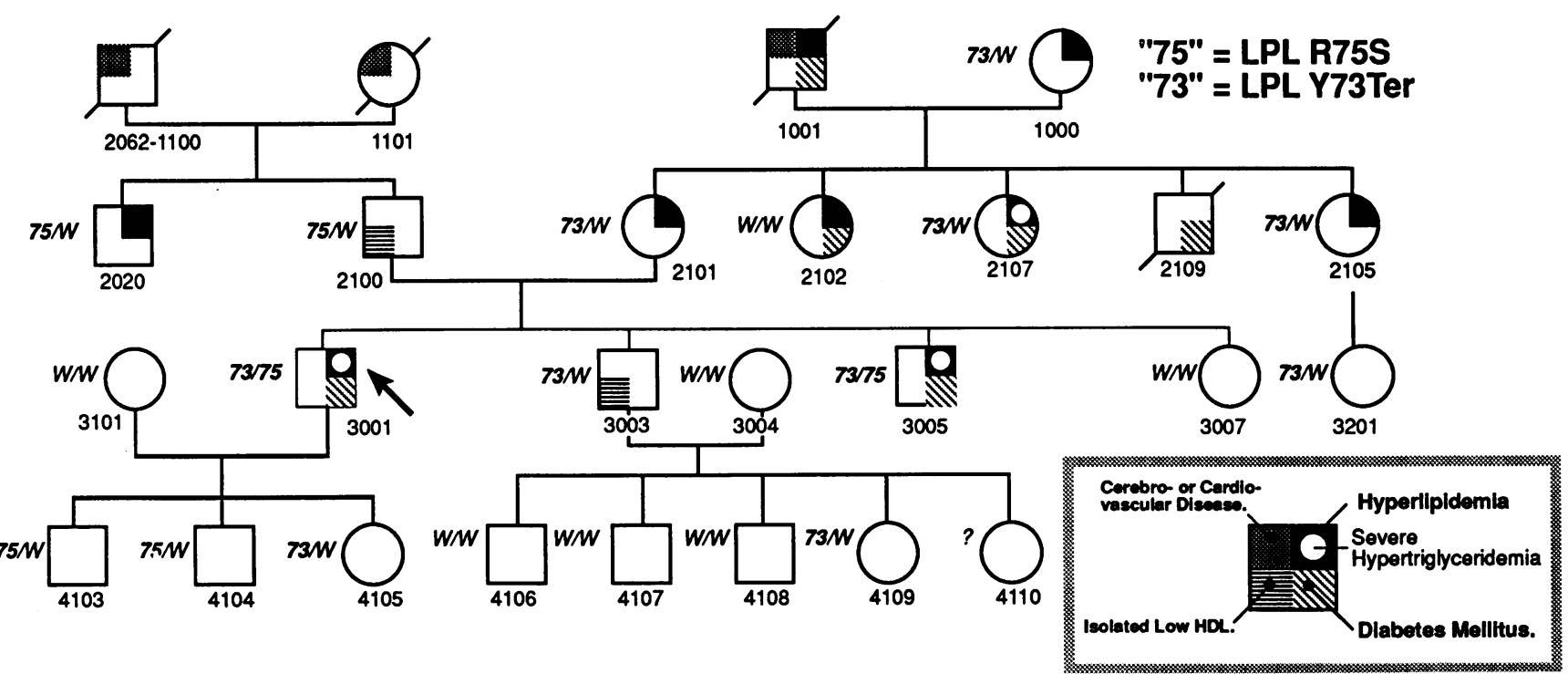

Figure 1. Kindred 2062. Subject numbers are indicated below the symbols for male ( $\square$ ) and female (O) subjects, and alleles (W, wild-type; 73, Y73Ter; 75, R75S) to their left. Conventions for clinical conditions (hyperlipidemia, severe hypertriglyceridemia, diabetes mellitus, cerebroor cardiovascular disease, and isolated low HDL) are indicated in the figure key. 
enzyme and mixed with a gentle stream of moistened air delivered through fine polyethylene tubing. Active bovine LPL standards (stored at $-20^{\circ} \mathrm{C}$ in $50 \%$ glycerol $/ 50 \%$ PBS at a protein concentration of 50 $\mu \mathrm{g} / \mathrm{ml}$ ) were included in each series of assays. Catalytic rates were calculated from the change in optical density at $401.5 \mathrm{~nm}$ and corrected for spontaneous hydrolysis. Specific activities against PNPB and triolein were either calculated directly from raw data, or when appropriate, from the summed trapezoidal areas for activity and mass in the eluted peaks, after correction for background and baseline-drift.

Screening for molecular variants. Exons 3, 4, 5, and 6 were screened for mutations by polyacrylamide gel electrophoresis essentially as described by Orita et al. $(30,31)$. Genomic DNA was first enzymatically amplified in 20- $\mu \mathrm{l}$ reactions each containing (per $100 \mu \mathrm{l}$ ): $10 \times \mathrm{Taq}$ buffer (Cetus Corp., Emeryville, CA) $10 \mu$; dNTP's (1.25 mM) forward and reverse primers $1 \mu \mathrm{M}$; Taq polymerase (Cetus Corp.); [ $\left.{ }^{32} \mathrm{P}\right]-$ dCTP and DNA, $1 \mu \mathrm{g}$. The reactions were terminated by the addition of $72 \mu \mathrm{l}$ of formamide/SDS/EDTA containing bromphenol blue and xylene cyanole. The products were then denatured by heating at $95^{\circ} \mathrm{C}$ for $6 \mathrm{~min}$, electrophoresed under nondenaturing conditions on $5 \%$ polyacrylamide gels, and visualized by autoradiography.

Anomalous bands from the proband's pattern were eluted and amplified using primers encompassing exon 3, extended with sequence to the universal M13 priming site ( $5^{\prime}$-TGTAAAACGACGGCCAGT-3'). Sequencing was performed by thermocycling with Taq polymerase and dideoxy chain termination; the electrophoretically separated products were analyzed with an ABI 373A DNA sequencer (Applied Biosystems, Inc., Foster City, CA).

Oligonucleotide probes complementary to wild-type and mutant alleles were synthesized in a model 380A DNA synthesizer (Applied Biosystems, Foster City, CA) and ${ }^{32}$ P-end-labeled.

\section{LP73N 5'-GCC CTG TAC AAG AGA GA-3' \\ LP73M 5'-TC TCT CTT TTA CAG GGC-3' \\ LP75N 5'-TC TGG TTC TCT CTT GTA-3' \\ LP75M 5'-TAC AAG AGC GAA CCA GA-3'}

Aliquots $(15 \mu \mathrm{l})$ of genomic DNA were enzymatically amplified using exon 3 forward and reverse flanking primers. The product was denatured in $200 \mu$ l of $0.4 \mathrm{M} \mathrm{NaOH} / 25 \mathrm{mM}$ EDTA and $90 \mu$ l of the mixture were spotted in duplicate onto a nylon membrane (BioTrace RP, Gelman Sciences, Inc., Ann Arbor, MI) using a Bio-Dot SF apparatus (Bio-Rad Laboratories, Richmond, CA). After neutralization with 90 $\mu \mathrm{l}$ of $3 \mathrm{M} \mathrm{Na}$-acetate buffer ( $\mathrm{pH}$ 5.4), DNA was cross-linked to the membrane in a Stratalinker 1800 (Stratagene, Inc., La Jolla, CA). The labeled probes were hybridized to the membrane in the presence of $0.5 \%$ SDS $/ 0.9 \mathrm{M} \mathrm{NaCl} / 1 \mathrm{mM}$ EDTA/50 mM Na-phosphate buffer (pH 7.2) at $37^{\circ} \mathrm{C}$ for $3 \mathrm{~h}$. After hybridization, the membranes were washed two times in $0.15 \mathrm{M} \mathrm{NaCl} / 15 \mathrm{mM} \mathrm{Na}$-citrate buffer ( $\mathrm{pH} 7.0$ ) at room temperature, and then washed at 1 to $2^{\circ} \mathrm{C}$ below the calculated melting temperatures for the mutant and normal alleles, respectively, and submitted to autoradiography.

Expression in COS-1 cells. The missense allele was expressed in cultured COS- 1 cells (ATCC Catalogue No. CRL1650) plated at an initial density of $1 \times 10^{6}$ per $10-\mathrm{cm}$ dish and maintained in $5 \mathrm{ml}$ of Dulbecco's modified Eagle's medium (DME, Gibco, Grand Island, NY) with $10 \%$ FCS for $48 \mathrm{~h}$. They were transfected with plasmid DNA $(6 \mu \mathrm{g} /$ dish ) following the DEAE-dextran protocol of Selden et al. (32) with modification. $1 \mathrm{~h}$ after DNA addition, chloroquine was added to the medium at a final concentration of $80 \mu \mathrm{M}$. After $4 \mathrm{~h}$ of incubation at $37^{\circ} \mathrm{C}, 5 \mathrm{ml}$ of $10 \% \mathrm{DMSO} / \mathrm{PBS}$ was added to each plate for $2 \mathrm{~min}$ at room temperature. After aspiration of this solution, each plate was washed with $5 \mathrm{ml}$ of $1 \times$ PBS. This solution was replaced with $5 \mathrm{ml}$ of complete medium and the culture was incubated at $37^{\circ} \mathrm{C} .30 \mathrm{~h}$ after transfection, $5 \mathrm{ml}$ of serum-free DME medium with heparin at a final concentration of $5 \mathrm{U} / \mathrm{ml}$, was substituted and the culture incubated for another $8 \mathrm{~h}$ before medium and cells were harvested. Cell extracts were prepared by washing the cells twice with $1 \times$ PBS, adding $1 \mathrm{ml}$ of cell lysis buffer $[2 \mathrm{mg} / \mathrm{ml}$ deoxycholic acid, $0.08 \mathrm{mg} / \mathrm{ml}$ Nonidet P-40, $0.05 \mathrm{mg} / \mathrm{ml}$ heparin, $0.1 \mathrm{M}$ Hepes buffer $(\mathrm{pH} 7.5)$ ] per plate, and detaching cells with a cell scraper. The cell extracts were homogenized in a Dounce tissue grinder, centrifuged at $\sim 15,000 \mathrm{~g}$ for $10 \mathrm{~min}$ at $4^{\circ} \mathrm{C}$, and the supernatants were collected. The media and cell extracts were flash-frozen and stored at $-70^{\circ} \mathrm{C}$ until analyzed.

\section{Results}

Plasma lipids and lipoproteins from the nuclear family are shown in Table I. The proband's (subject no. 3001) values were typical for type I hyperlipoproteinemia. His two sons (4103 and 4104) were normolipidemic, consistent with observations in young carriers of the G188E mutation previously reported $(20,22)$. On the first sampling the 11 -yr-old daughter (4105) had increased age- and gender-specific total and LDL cholesterol concentrations $(=95$ th percentile and $>95$ th percentile, respectively). This pattern, with hypertriglyceridemia in some family members and hypercholesterolemia others, could be consistent with FCH (33). However, when the daughter was retested 1 yr later without any interim dietary changes, her values were entirely normal (second values in Table I).

Preheparin plasma LPL mass in the proband, determined by competitive ELISA and normalized to a bovine LPL standard, was $19 \mathrm{ng} / \mathrm{ml}$ rising after heparin administration to 51 $\mathrm{ng} / \mathrm{ml}$, a value lower than previously reported for normal subjects (21), and similar to mean values reported for LPL-deficient subjects inferred to have catalytically defective enzyme protein (26). Postheparin plasma LPL activity in the proband was severely reduced $(13 \mathrm{nmol} / \mathrm{ml}$ per $\mathrm{min}, \sim 6 \%$ of the reported normal mean) whereas hepatic triglyceride lipase activity was $370 \mathrm{nmol} / \mathrm{ml}$ per min, within the range of normal subjects in this laboratory.

No mutations were revealed in exons 4,5 , or 6 (data not shown) by chromatographic analysis of enzymatically amplified genomic DNA from the proband (3001), his offspring $(4103,4104,4105)$, or their mother $(3101)$. On analysis of exon 3 (Fig. 2) the mother, 3101, exhibited two major bands identical with those in normolipidemic controls, whereas the proband had four bands, two of which were clearly different from hers. The two sons possessed one of the anomalous paternal bands, and their daughter the other. This suggested that the proband was a compound heterozygote for two different mutant alleles, and that his offspring were obligate heterozygotes for one or the other of them.

The proband's two abnormal bands were eluted from polyacrylamide gel and used as templates for thermocycling reactions with primers flanking exon 3 , lengthened with the universal M13 priming sequence ( 5 '-TGTAAAACGACGGCCAGT$\left.3^{\prime}\right)$. Automated dideoxy sequencing showed that the proband bore two mutant alleles, one at nt $480(\mathrm{~A} \rightarrow \mathrm{C})$ coding for a ${ }^{75} \mathrm{Arg} \rightarrow$ Ser substitution, and the other at $\mathrm{nt} 474(\mathrm{C} \rightarrow \mathrm{A})$ changing ${ }^{73} \mathrm{Tyr}$ to a stop codon. These conclusions were confirmed by hybridization with allele-specific oligonucleotide probes complementary to the mutant alleles (Fig. 2).

The functional significance of the R75S mutation was investigated through transient expression of wild-type (arginine $^{75}$ ) and mutant (serine ${ }^{75}$ ) LPL sequences in transfected COS- 1 cells. Measured LPL masses in medium and cell lysate from R75S-transfected cells ( 242 and $742 \mathrm{ng} / \mathrm{ml}$, respectively) were of the same order as those measured with wild-type-transfected cells ( 675 and $764 \mathrm{ng} / \mathrm{ml}$, respectively). Activity from 
Table I. Laboratory Data, Relevant Illnesses, Medications, and Habits in the Proband (3001)

in Kindred 2062, His Offspring (4103-4105), Their Mother (3101), and Members of the Extended Pedigree

\begin{tabular}{|c|c|c|c|c|c|c|c|c|c|c|}
\hline $\begin{array}{l}\text { Subject } \\
\text { Number }\end{array}$ & Age & Sex & Mutation & Triglycerides & $\begin{array}{l}\text { VLDL } \\
\text { cholesterol }\end{array}$ & $\begin{array}{c}\text { Total } \\
\text { cholesterol }\end{array}$ & $\begin{array}{c}\text { LDL } \\
\text { cholesterol }\end{array}$ & $\begin{array}{c}\text { HDL } \\
\text { cholesterol }\end{array}$ & Glucose & Illnesses, drugs, habits \\
\hline 1000 & 87 & $\mathbf{F}$ & $73 / \mathrm{W}$ & 183 & 51 & 180 & 98 & 28 & 92 & $\begin{array}{l}\text { Peripheral neuropathy. BUN 27, } \\
\text { on furosemide }\end{array}$ \\
\hline 1001 & 74 & $\mathbf{M}$ & - & - & - & - & - & - & - & Deceased. Diabetes mellitus \\
\hline 1100 & 79 & $\mathbf{M}$ & - & - & - & - & - & - & - & Deceased. "Heart attack, stroke" \\
\hline 1101 & 63 & $\mathrm{~F}$ & - & - & - & - & - & - & - & Deceased. "Heart attack" \\
\hline 2020 & 69 & $\mathbf{M}$ & $75 / \mathrm{W}$ & 342 & 71 & 189 & 75 & 27 & 100 & Hypertension, on nifedipine \\
\hline 2100 & 71 & $\mathbf{M}$ & $75 / W$ & 136 & 46 & 180 & 113 & 29 & 97 & Healthy \\
\hline 2101 & 66 & $\mathbf{F}$ & $73 / \mathrm{W}$ & 521 & 108 & 215 & 64 & 38 & 97 & Premarin $0.625 \mathrm{mg} /$ day \\
\hline 2102 & 64 & $\mathrm{~F}$ & $\mathbf{W} / \mathbf{W}$ & 415 & 120 & 222 & 82 & 36 & 145 & $\begin{array}{l}\text { Diabetes mellitus on insulin: } \\
\mathrm{HbA}_{\mathrm{lc}} 8.4 \% \text {. Pancreatitis, } \\
\text { treated hypothyroidism }\end{array}$ \\
\hline 2105 & 62 & $\mathrm{~F}$ & $73 / \mathrm{W}$ & 260 & 42 & 237 & 115 & 32 & 83 & $\begin{array}{l}\text { Treated hypothyroidism. Lipid- } \\
\text { lowering diet }\end{array}$ \\
\hline 2107 & 51 & $\mathrm{~F}$ & $73 / \mathrm{W}$ & 5,310 & 633 & 655 & 10 & 10 & 122 & $\begin{array}{l}\text { Diabetes mellitus on insulin. } \\
\mathrm{HbA}_{\mathrm{lc}} 10.6 \% \text {. Abdominal } \\
\text { pain, hypertension, } \\
\text { retinopathy, pancreatitis }\end{array}$ \\
\hline 2109 & - & $\mathbf{M}$ & - & - & - & - & - & - & - & $\begin{array}{l}\text { Accidental death. Diabetes } \\
\text { mellitus }\end{array}$ \\
\hline 3001 & 44 & $\mathbf{M}$ & $73 / 75$ & 1,478 & 79 & 124 & 18 & 10 & 87 & $\begin{array}{l}\text { Proband. Diabetes, pancreatitis. } \\
\text { On gemfibrozil, glyburide }\end{array}$ \\
\hline 3003 & 40 & $\mathbf{M}$ & $73 / \mathrm{W}$ & 76 & 28 & 123 & 67 & 29 & 90 & Healthy \\
\hline 3004 & 44 & $\mathrm{~F}$ & $\mathrm{~W} / \mathrm{W}$ & 163 & 48 & 214 & 113 & 51 & 86 & Healthy, unrelated spouse \\
\hline 3005 & 39 & $\mathbf{M}$ & $73 / 75$ & 2,394 & 257 & 282 & 25 & 8 & 120 & $\begin{array}{l}\text { Brother of proband. Lifelong } \\
\text { hyperlipidemia, not known to } \\
\text { have diabetes }\end{array}$ \\
\hline 3007 & 42 & $\mathrm{~F}$ & $\mathrm{~W} / \mathrm{W}$ & 83 & 24 & 150 & 81 & 37 & 95 & Healthy \\
\hline 3101 & 49 & $\mathrm{~F}$ & $\mathbf{W} / \mathbf{W}$ & 91 & 25 & 235 & 131 & 86 & 87 & Healthy ex-spouse of proband \\
\hline 3201 & 40 & $\mathrm{~F}$ & $73 / \mathrm{W}$ & - & - & - & - & - & - & $\begin{array}{l}\text { Abdominal pain, treated } \\
\text { hypothyroidism. Blood } \\
\text { samples lost in mail }\end{array}$ \\
\hline 4103 & 15 & $\mathbf{M}$ & $75 / W$ & 83 & 16 & 169 & 117 & 41 & 96 & Healthy \\
\hline 4104 & 13 & $\mathbf{M}$ & $75 / \mathrm{W}$ & 65 & 12 & 159 & 114 & 46 & 89 & Healthy \\
\hline 4105 & 11 & $\mathrm{~F}$ & $73 / \mathrm{W}$ & 96,82 & 19 & 205,167 & 145,106 & 55,45 & 67 & Healthy \\
\hline 4106 & 11 & $\mathbf{M}$ & $\mathrm{W} / \mathrm{W}$ & 66 & 27 & 174 & 83 & 61 & 101 & Healthy \\
\hline 4107 & 13 & $\mathbf{M}$ & $\mathbf{W} / \mathbf{W}$ & 41 & 22 & 142 & 63 & 56 & 85 & Healthy \\
\hline 4108 & 14 & $\mathbf{M}$ & $\mathbf{W} / \mathbf{W}$ & 190 & 44 & 153 & 71 & 39 & 90 & Healthy \\
\hline 4109 & 8 & $\mathrm{~F}$ & $73 / \mathrm{W}$ & 89 & 44 & 168 & 107 & 41 & 85 & Healthy \\
\hline 4110 & 6 & $\mathrm{~F}$ & $?$ & - & - & - & - & - & - & Blood not drawn \\
\hline
\end{tabular}

Total cholesterol in the daughter (4105) exceeded the 90th percentile and LDL cholesterol the 95th percentile Lipid Research Center upper cutpoints, respectively, for her age and gender on the first sampling, but were entirely normal 13 months later (second set of values). Abbreviations: BUN, blood urea nitrogen; W, wild-type allele; 73, Y73Ter allele; 75, R75S allele.

the R75S-transfected cells, however, was $<1 \%$ of that observed in cells expressing the normal sequence ( 1 and 1 [mutant] vs. 144 and 167 [wild-type] $\mathrm{nmol} / \mathrm{ml}$ per min, for media and cell lysates, respectively).

LPL mass and activity were examined further in fractions separated by heparin-Superose affinity chromatography. Immunoreactive LPL mass in media from wild-type-transfected cells eluted in two peaks of similar magnitude at $\mathrm{NaCl}$ concentrations of $\sim 0.5$ and $\sim 1.0 \mathrm{M}$ (Fig. 3 ). The second, higher-affinity peak catalyzed the hydrolysis of both triolein in the presence of serum activator, and micellar PNPB in the absence of added serum. The first peak had no detectable enzymatic activ- ity against either substrate. In contrast to media from wildtype-transfected COS-1 cells, medium from those transfected with R75S mutant LPL exhibited a large, low-affinity mass peak and markedly reduced but detectable immunoreactive LPL in the second, higher-affinity peak. As with wild-type LPL, fractions in peak I were catalytically inactive. Peak II fractions from media of R75S transfectants exhibited low activity against triolein which was nevertheless significantly above background for the assay.

Cell lysates and media from wild-type-transfected COS-1 cells showed esterase activity against PNPB in the early fractions (1-20) of the heparin-Superose chromatogram (Fig. 4). 


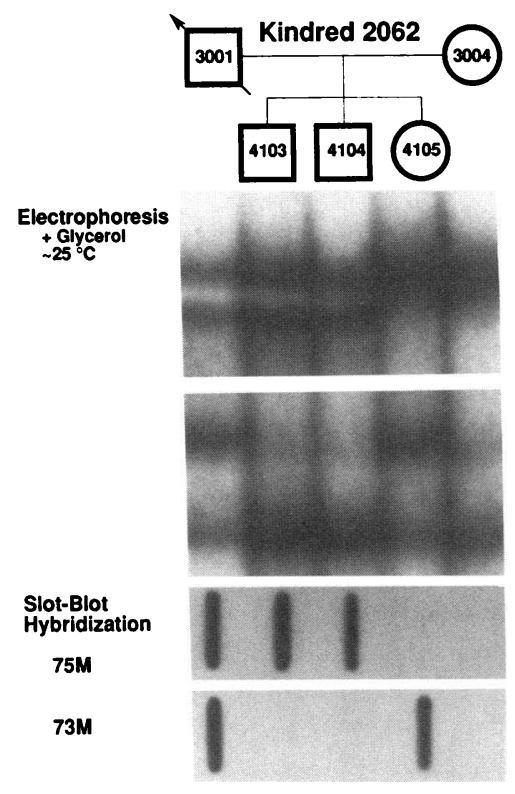

Figure 2. Detection of mutant alleles in kindred 2062 by singlestranded conformation polymorphism and slotblot hybridization with oligonucleotide probes specific for mutant and wild-type sequences (see Methods). Genomic DNA was amplified in the presence of $\mathrm{Taq}$ polymerase, $\left[{ }^{32} \mathrm{P}\right] \mathrm{dCTP}$, and primers flanking LPL exon 3, denatured in the presence of formamide, and the resulting single-stranded DNA was subjected to electrophoresis on $5 \%$ polyacrylamide at room temperature in the presence of $10 \%$ glycerol.

Noninformative regions of the autoradiogram were excised from the photograph. Electrophoresis at $2^{\circ} \mathrm{C}$ in the absence of glycerol (data not shown) confirmed the presence of different paternal alleles in the sons (4103 and 4104), and the daughter (4105). The maternal pattern was identical to that of random controls.

This activity was not inhibited by the addition of anti-bovine LPL antibody (7640A) under conditions that inhibited bovine LPL by $87 \%$ (data not shown) and thus, appeared to be nonspecific. Since the majority of the nonspecific esterase activity eluted from the column in the first $20 \mathrm{ml}$, LPL-catalyzed PNPB hydrolysis could be identified as a distinct peak of activity eluting at the same molarity as LPL activity and mass (peak II) in the standard assay (Fig. 4). No peak of PNPB hydrolysis was observed to coincide with peak I. The rate of hydrolysis of PNPB relative to triolein by peak II fractions from R75S-transfected cell medium was similar to that observed for wild-type transfection ( 4.8 vs. $3.3 \mathrm{pmol} / \mathrm{min}$ per ng LPL protein, respectively; Figs. 3 and 4 ). When serum activator was omitted, the hydrolysis of triolein by peak II fractions from R75S-transfected media was reduced $83 \%$ by peak-area comparison (fractions eluting between 30 and $32 \mathrm{ml} ; 8.83 \mathrm{nmol} / \mathrm{min}$ per $\mathrm{ml}$ vs. 1.74 for assays with and without serum, respectively) consistent with apoC-II dependence, and implying that apoC-II was binding to the mutant enzyme. Although these results with R75S may not be quantitatively precise, having been performed at the limit of assay sensitivity, the two experiments nevertheless led to the same conclusion.

Thus, as with previously reported missense mutations from our own and other laboratories $(18,22,34), \mathrm{R} 75 \mathrm{~S}$ resulted in the production of a catalytically inactive protein having reduced affinity for heparin (Fig. $3 \mathrm{~B}$ ). There was, however, a second, higher-affinity species secreted into the culture medium and representing a small fraction of the total mass, that was shown to be catalytically active (eluting at $\sim 31-32 \mathrm{ml}$, Figs. $3 B$ and $4 B$ ).

Screening of the extended pedigree (Table I and Fig. 1) revealed that the 73 truncation was segregating in the proband's maternal line while the 75 -missense mutation was found among the paternal ancestors. Alcohol and tobacco use
A. WILD-TYPE.

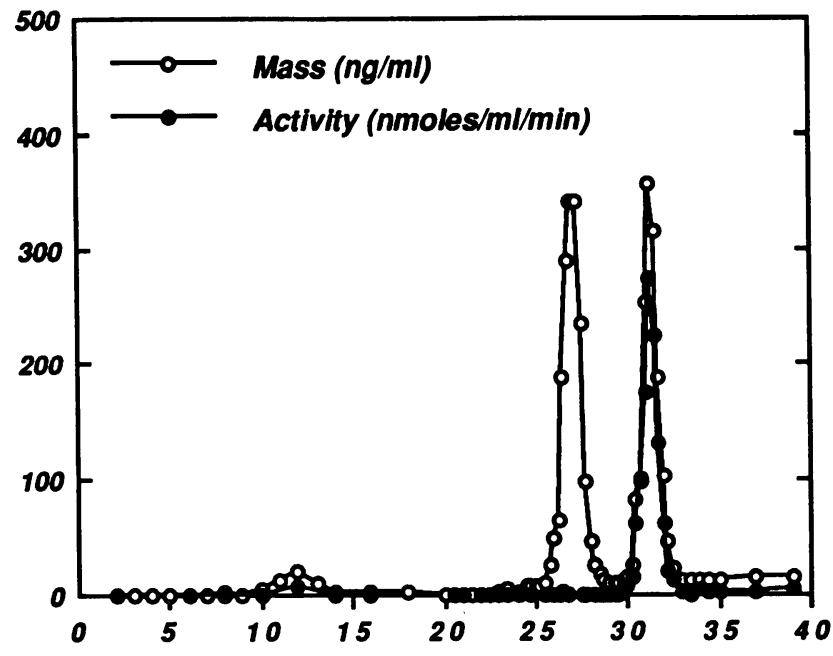

\section{B. R75S MUTANT.}

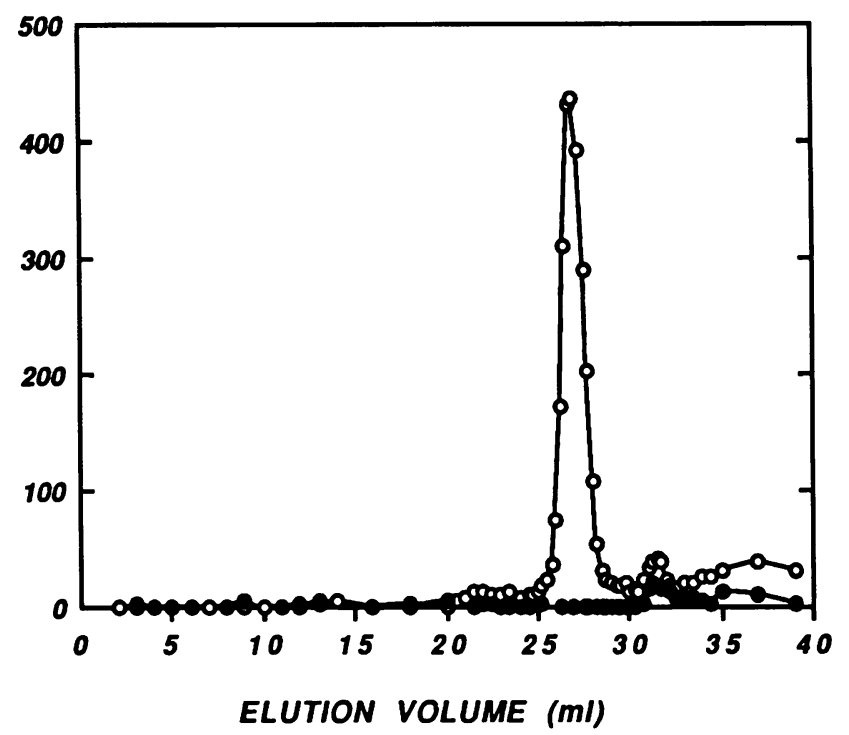

Figure 3. Affinity chromatography of conditioned media from $(A)$ cultured wild-type and $(B)$ R75S-transfected COS-1 cells on heparinSuperose. Media were harvested and chromatographed as described in Methods. The eluted fractions were assayed for mass by ELISA, and for catalytic activity against emulsified triolein in the presence of serum, a source of apoC-II. The results were normalized to recovered mass. Calculated LPL mass recoveries for the estimated load were $56 \%$ for wild-type enzyme and $64 \%$ for the mutant. For the wild-type transfectant, $44 \%$ of the load was in peak I (fractions from 25.5 to $29.0 \mathrm{ml}$ ) and $38 \%$ in peak II (fractions from 30.0 to 33.0 $\mathrm{ml}$ ), accounting for $82 \%$ of the recovered mass. For the R75S transfectant, $65 \%$ was measured in peak I and only $8 \%$ in peak II, accounting for $73 \%$ of the recovered mass. Note the tiny peak of activity and mass eluting at $31.25 \mathrm{ml}$ with medium from R75S-transfected cells. Averaged raw specific activities against triolein, calculated across the active region (peak II; elution volume $30.75-31.75 \mathrm{ml}$ ), were 0.77 and $0.40 \mathrm{nmol} / \mathrm{min}$ per $\mathrm{ng}$ for wild-type and mutant enzymes, respectively.

were minimal. With the possible exception of the paternal grandmother (1101) there was no suggestion of premature cardiovascular mortality. Indeed the maternal grandmother, alive and relatively healthy at $87 \mathrm{yr}$ of age, carried the LPL trunca- 
A. WILD-TYPE.

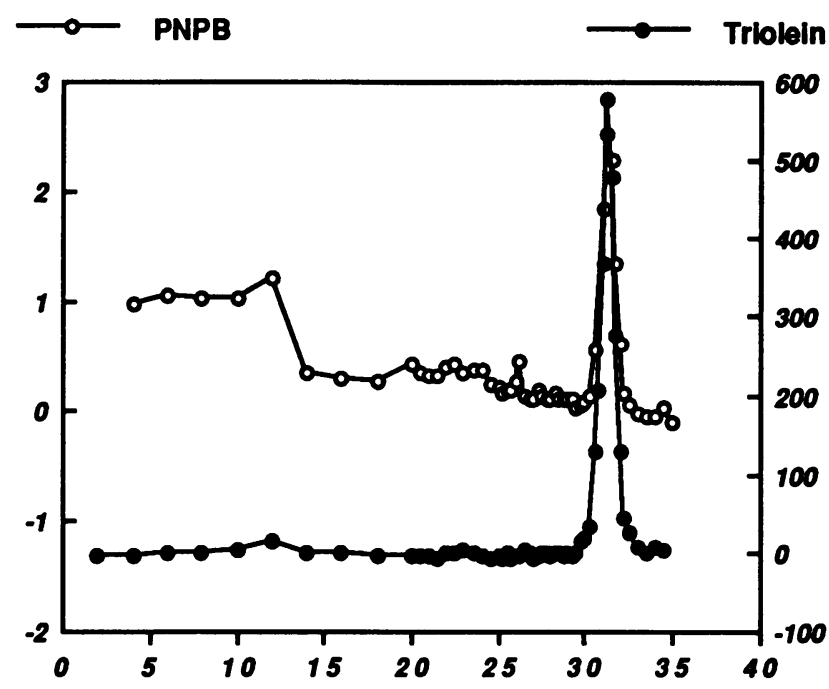

B. R75S MUTANT.

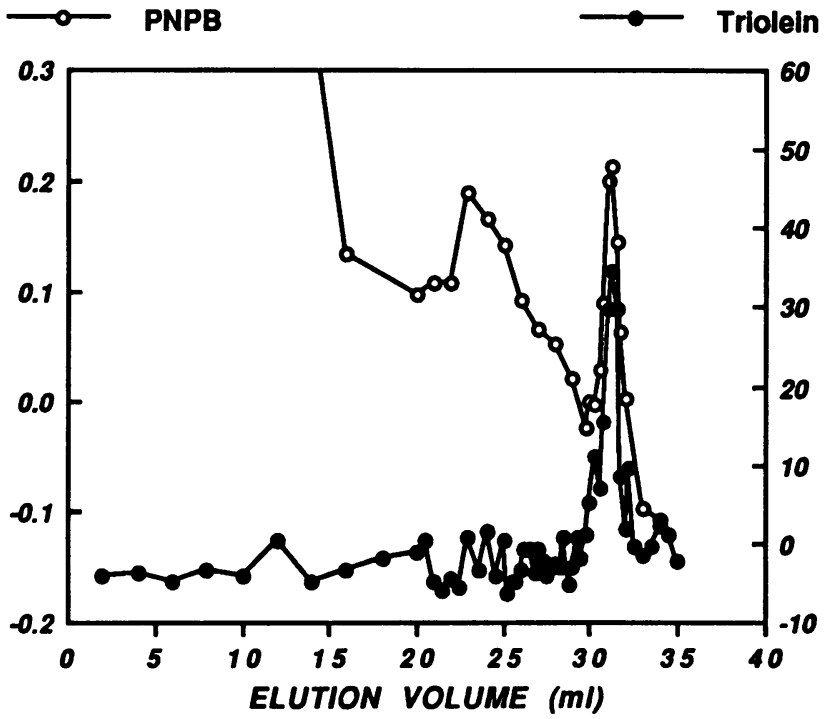

Figure 4. Affinity chromatography of conditioned media from $(A)$ cultured wild-type and $(B)$ R75S-transfected COS-1 cells on heparinSuperose, as in Fig. 3. The eluted fractions were assayed for hydrolase activity against emulsified triolein in the presence of serum, and against micellar PNPB as indicated in Methods. Triolein specific activities calculated from the areas for mass and activity under peak II (elution volume $29.5-33.0 \mathrm{ml}$.) after correction for background, were 0.78 and $0.64 \mathrm{nmol} / \mathrm{min}$ per $\mathrm{ng}$ for wild-type and mutant enzymes, respectively. For PNPB, the specific activities, similarly calculated, were 3.3 and $4.8 \mathrm{pmol} / \mathrm{min}$ per $\mathrm{ng}$ for wild-type and mutant enzymes, respectively.

tion. As in our previous study of kindred 2003 with the G188E mutation (20), none of the carriers was hypertriglyceridemic before the age of $40 \mathrm{yr}$. The proband's 40 -yr-old brother ( 3003 ) and 71-yr-old father (2100) had asymptomatic, isolated reductions in HDL cholesterol. Estrogen use may have exacerbated hypertriglyceridemia in his mother (2101) who carried the 73 truncation.

Diabetes and hyperlipidemia appeared to segregate independently in the maternal lineage; two living individuals were veri- fiably affected with diabetes and two deceased individuals had been diabetic by history. All members of the parental generation in the maternal lineage (five individuals numbered 2101, 2102,2105 , and 2107, and deceased 2109) exhibited diabetes mellitus, hyperlipidemia, or both. One individual (2102) with diabetes who was homozygous for the wild-type LPL allele, had moderate hypertriglyceridemia $(415 \mathrm{mg} / \mathrm{dl})$. Two individuals unaffected by diabetes but who carried of the Y73Ter mutation ( 2101 and 2105, females aged 66 and $62 \mathrm{yr}$, respectively) also had mild-to-moderate hypertriglyceridemia ( 521 and $260 \mathrm{mg}$ / dl). Subject 2107, a 50-yr-old woman with both insulin-treated diabetes and severe hypertriglyceridemia $(5,310 \mathrm{mg} / \mathrm{dl})$, had eruptive xanthomas and a history of pancreatitis; she proved to be a carrier of Y73Ter. Her plasma triglyceride value is the highest recorded among a total of 40 carriers in our own data, including 11 from the present study and 29 carriers from pedigree 2003 (20), consistent with an additive or synergistic effect of diabetes on the phenotypic expression of the mutant LPL allele.

\section{Discussion}

A previously unreported patient with type I hyperlipoproteinemia presented as an adult with a history of hypertriglyceridemia and abdominal pain beginning in childhood, and episodes of documented pancreatitis and NIDDM (type II diabetes mellitus) of adult onset. It is possible that type I hyperlipoproteinemia, through repeated bouts of pancreatitis, might lead to pancreatogenous diabetes. However, a family history of NIDDM in nonhypertriglyceridemic members and lack of evidence for pancreatic calcification or exocrine deficiency in the propositus make this interpretation an unlikely sole explanation for the occurrence of diabetes (35). This same argument can be applied to other hypertriglyceridemic diabetic pedigree members. Conversely, independently inherited NIDDM, leading to increased production of triglyceride-rich lipoproteins (36), could be expected to exacerbate hypertriglyceridemia in the presence of defective LPL alleles $(23,24,37)$.

The proband and a younger brother were discovered to be compound heterozygotes for two previously undescribed mutations in the LPL gene. Both were in exon 3: one was missense (R75S) whereas the other (Y73Ter) resulted in a premature stop codon. On the basis of these and other recently reported mutations ( $38-40$ ), exon 3 must be included with exons 4-6 in the highly conserved region coding for residues in the first folding domain, a region whose integrity is evidently critical to the function of the mature enzyme. Missense mutations that directly involve residues participating in catalysis are the exception: $\operatorname{Asp}^{156}$ (D156N [15] and D156G $\left.[15,16]\right)$ situated in the catalytic triad-homologue of pancreatic lipase (41) are the only known examples. Thus other mechanisms must be invoked to explain enzyme deficiency caused by the majority of these substitutions. In principle, such mutations could involve any of several discrete functional domains: those binding the LPL cofactor, apoC-II, heparin, or lipid substrates (1). The missense R75S sequence was therefore transfected into COS-1 cells so that properties of the mutant LPL recovered from media and cell extracts could be studied.

Since wild-type LPL requires apoC-II for full activity, the existence of an apoC-II binding site on LPL has been postulated. The site has recently been localized to the $\mathrm{NH}_{2}$-terminal, first folding-domain by analysis of chimeric enzymes (14). 
Candidate regions include the $\mathrm{NH}_{2}$-terminal 50 residues and sequences with high positive charge ( $\mathrm{R}$ or $\mathrm{K})$ including consensus heparin-binding sites (42). Nevertheless, examples of mutations in a putative apoC-II-binding region have not been documented nor has the apoC-II-binding domain been delineated experimentally. The measurable amounts of active, high heparin-affinity $\mathrm{R} 75 \mathrm{~S}$ product detected in media allowed us to test whether or not this mutation might affect activation by apoC-II. Two lines of evidence argue against this possibility. First, the omission of serum (the source of apoC-II in the assay) reduced activity $(\sim 80 \%)$ against triolein with both mutant and wild-type enzymes, indicating their dependence on apoC-II. Second, since apoC-II is required for maximal hydrolysis of triolein, but not short chain fatty acid esters such as PNPB $(27,28)$, disproportionate hydrolysis of PNPB by lysates or media from R75S-transfected cells would have been expected with an apoC-II binding-defective mutant. The relative rates of hydrolysis of PNPB and triolein proved similar for the R75S and wild-type enzymes from transfected COS-1 cell media, however, making it highly improbable that the R75S mutation affected apoC-II-binding.

Affinity chromatography of culture media on heparin-Superose distinguished two species of LPL: $(a)$ a lower-affinity peak having no detectable enzymatic activity and $(b)$ a higheraffinity peak with activity against triolein. In contrast to media from cultured wild-type transfectants in which immunoreactive mass was roughly equal in the two peaks (Fig. $3 \mathrm{~A}$ ), the inactive, low-affinity peak accounted for the great majority of total immunoreactive mass in media from R75S transfectants (Fig. $3 \mathrm{~B}$ ). Nevertheless, the specific activity of the R75S mutant against triolein, calculated for the higher-affinity peak, was of the same order as wild-type enzyme $(0.40$ vs. $0.77 \mathrm{nmol} /$ min per ng LPL mass). Thus, a small amount of catalytically competent R75S enzyme was secreted.

What are the molecular species in the two peaks eluted from heparin-Superose, one active and the other not? A great deal of evidence (43-49), summarized by Hata et al. (18), supports the conclusion that active LPL consists of two monomeric subunits combined as a homodimer at physiological $\mathrm{pH}$ and ionic strength $(45,48)$, possibly oriented in a head-to-tail configuration (50). Other evidence indicates that enzymatically active LPL has a higher affinity for heparin than does inactive LPL (51). Thus we concluded that the higher affinity, enzymatically active peak eluting from heparin-Sepharose may be present as a homodimer under conditions of the assay (18). However LPL is likely to dissociate into its subunits at $\mathrm{NaCl}$ concentrations of $0.8 \mathrm{M}$ or more (52-54). Therefore LPL may emerge from the column as a stable, dissociated monomer when it is eluted with $\sim 1.0 \mathrm{M} \mathrm{NaCl}$, and then reassociate into the active dimer when it is diluted in the activity-assay buffer. The lower-affinity peak of wild-type LPL, which never exhibits activity, may therefore be irreversibly denatured.

Insight into the mechanism by which missense mutations result in the loss of LPL activity has been provided by pulsechase experiments with four naturally occurring mutations in exon 5 (A176T, G188E, G195E, and S244T) expressed in COS-1 cells (18). With one exception, G188E, the mutant products consisted solely of the low heparin-affinity species. With G188E, small amounts of active enzyme with high binding affinity for heparin could be recovered from cell lysates by loading large volumes; however there was no evidence for any active enzyme secreted into media. With all four mutants, im- munoprecipitable ${ }^{35} \mathrm{~S}$-labeled LPL protein appeared promptly in cell lysates, in amounts comparable to those expressed by wild-type transfectants, and disappeared with a similar time course. Thus, it was apparent that the synthesis and disappearance of the inactive polypeptide chains was not grossly disturbed. The amount of mutant protein secreted, estimated from the appearance of ${ }^{35} \mathrm{~S}$-labeled LPL in the media, was variably reduced, most severely with A176T and S244T, and least with G188E and G195E. Thus, these exon 5 mutations all led to the production of an inactive species with reduced affinity for immobilized heparin. These mutations, spanning 68 residues in the primary LPL sequence, are all located in the highly conserved, $\mathrm{NH}_{2}$-terminal folding domain of the enzyme.

Since it seemed unlikely that these mutations could all be members of a circumscribed functional element, we concluded that they disturbed overall protein conformation and stability. The foregoing evidence was interpreted as consistent with defective assembly or reduced stability of the active, high-affinity dimeric species within cells and in media. Using parallel arguments we now conclude that $R 75 \mathrm{~S}$ also results in the synthesis of an intrinsically unstable enzyme. However, COS-1 cells transfected with the new missense mutation showed one interesting difference from those studied previously. In contrast to A176T, S244T, G188E, and G195E, small amounts of catalytically active LPL were detected as a high heparin-affinity species in media from cells bearing $\mathrm{R} 75 \mathrm{~S}$.

The four LPL mutations previously reported, along with R75S, thus appear to represent a class of inherently unstable enzyme molecules, exhibiting a continuum of functional impairment. The most severe of these was S244T from which no activity whatsoever could be recovered, and in comparison to wild type, reduced amounts of the inactive species were secreted. R75S appears to be at the other end of this continuum, yielding substantial amounts of immunodetectable LPL protein in medium from COS-1 cells, small amounts of which retained catalytic activity.

The profound destabilizing effect of widely separated mutations in the first folding domain of LPL is consistent with the recognized importance of three-dimensional topology in the function of the lipases whose structure has been determined crystallographically, i.e., pancreatic lipase and fungal lipases. Despite undetectable sequence homology, human pancreatic and Geotrichum candidum lipases closely resemble each other in the conformation of their central $\beta$-sheet and in the location of two of the three residues (Ser, His) making up the catalytic triad (55); thus in these diverse representatives of the lipase superfamily $(55,56)$, overall topology is conserved even though their primary sequences diverge (55). The existence of stringent conformational requirements appears to explain how naturally occurring missense mutations, dispersed in the $\mathrm{NH}_{2}$-terminal folding domain of LPL and affecting residues unlikely to participate directly in catalytic or binding reactions, lead to lipoprotein lipase deficiency.

The phenotypes expressed in the extended pedigree were of interest. Two of the proband's offspring and a niece, heterozygous for the missense R75S allele, had entirely normal plasma lipid and lipoprotein concentrations. Of the seven carriers $40 \mathrm{yr}$ of age and older who were phenotyped, hypertriglyceridemia and/or reduced HDL cholesterol was detected in five, consistent with variable, age-dependent expression of familial hypertriglyceridemia in heterozygous carriers previously observed among $\mathrm{G} 188 \mathrm{E}$ carriers $(20,57)$. 
The proband's daughter (4105) who carried the null allele, had mildly increased total- and LDL cholesterol on one occasion, but not on repeat measurement. Even though this could be consistent with the phenotype, FCH (33), it could just as well be coincidental given the variability of plasma LDL during puberty and adolescence (58); it could also have been the result of laboratory error. Alternatively, different LPL mutations may eventually prove to have different associated phenotypes, a possibility that could account for the presence of increased LDL cholesterol in some pedigrees $(21,57)$ but not others (20). Nevertheless, lipid and lipoprotein analyses of genotypically proven heterozygotes have with rare exceptions (57) either been normal or have had hypertriglyceridemia, increased VLDL cholesterol, and reduced HDL cholesterol (type IV hyperlipoproteinemia) (5). Although final resolution of this issue will require study of a larger number of pedigrees with informative mutant alleles, evidence now available indicates that carriers of LPL mutations rarely if ever manifest $\mathrm{FCH}$.

Since an allele for an unstable mutant protein segregates in one branch of the pedigree while a null allele segregates in the other, one can also ask whether the secretion of low levels of catalytically competent enzyme such as demonstrated in vitro for the R75S mutation might delay or ameliorate the expression of hypertriglyceridemia. The clinical disorder observed in the proband's brother, also shown to be a compound heterozyote, is arguably milder than that described for classical LPL deficiency (19). Nevertheless, observations of other individuals affected by similar mutations would be necessary to establish that this is other than expected variation in the classical phenotype.

Finally, the data obtained in this pedigree bear on the hypothesis, introduced a number of years ago by Brunzell and others, that individuals with NIDDM manifesting severe lipemia have another independently inherited defect in lipoprotein metabolism $(23,24,37)$. Subject 2107 with severe hypertriglyceridemia, xanthomatosis, pancreatitis, and NIDDM appears to be the first documented example of the predicted result of segregating hyperlipidemia genes in diabetic individuals $(23,24)$. Her sibship fortuitously contained diabetic individuals without LPL mutant alleles, and nondiabetic carriers of LPL mutations. In neither of the latter instances did more than mild-tomoderate hypertriglyceridemia result. Thus, the role of independently segregating hyperlipidemia genes in the pathogenesis of severe diabetic hypertriglyceridemia can now be supported by direct evidence. It does not seem farfetched to anticipate that additional subjects with severe diabetic lipemia will be found to carry mutations in other genes affecting lipoprotein synthesis or removal, as well as additional dysfunctional LPL alleles.

\section{Acknowledgments}

We are grateful to Carol Bowcutt, R.N., and her staff on the Clinical Research Center, and to Kimberly Wegener for clinical coordination.

This work was supported by National Institutes of Health grants HL-45753, HL-39595, and RR-00064 to the Clinical Research Center, grants from the Department of Veterans Affairs (to Dr. Iverius and Wilson), and a grant-in-aid from the Nora Eccles Treadwell Foundation (to Dr. Wilson). Dr. Lalouel is an Investigator of the Howard Hughes Medical Institute.

\section{References}

1. Wion, K. L., T. G. Kirchgessner, A. J. Lusis, M. C. Schotz, and R. M. Lawn. 1987. Human lipoprotein lipase complementary DNA sequence. Science (Wash. DC). 235:1638-1641.

2. Kirchgessner, T. G., K. L. Svenson, A. G. Lusis, and M. C. Schotz. 1987. The sequence of cDNA encoding lipoprotein lipase. J. Biol. Chem. 262:84638466.

3. Deeb, S. S., and R. Peng. 1989. Structure of the human lipoprotein lipase gene. Biochemistry. 28:4131-4135.

4. Kirchgessner, T. G., J. C. Chuat, C. Heinzmann, J. Étienne, S. Guilhot, K. Svenson, D. Ameis, C. Pilon, L. d'Auriol, A. Andalibit, et al. 1989. Organization of the human lipoprotein lipase and evolution of the lipase gene family. Proc. Natl. Acad. Sci. USA. 86:9647-9651.

5. Lalouel, J. M., D. E. Wilson, and P. H. Iverius. 1992. Lipoprotein lipase and hepatic triglyceride lipase: molecular and genetic aspects. Curr. Opin. Lipidol. 3:86-95.

6. Devlin, R. H., S. Deeb, J. Brunzell, and M. R. Hayden. 1990. Partial gene duplication involving exon-Alu interchange results in lipoprotein lipase deficiency. Am. J. Hum. Genet. 46:112-119.

7. Langlois, S., S. Deeb, J. D. Brunzell, J. J. P. Kastelein, and M. R. Hayden. 1989. A major insertion accounts for a significant proportion of mutations underlying human lipoprotein lipase deficiency. Proc. Natl. Acad. Sci. USA. 86:96479651 .

8. Gotoda, T., N. Yamada, T. Murase, T. Inaba, S. Ishibashi, H. Shimano, S. Koga, Y. Yazaki, Y. Furuichi, and F. Takaku. 1991. Occurrence of multiple aberrantly spliced mRNAs upon a donor splice site mutation that causes familial lipoprotein lipase deficiency. J. Biol. Chem. 266:24757-24762.

9. Hata, A., M. Emi, G. Luc, A. Basdevant, P. Gambert, P. H. Iverius, and J. M. Lalouel. 1990. Compound heterozygote for lipoprotein lipase deficiency: Ser $\rightarrow$ Thr244 and transition in $3^{\prime}$ splice site of intron 2 (AG $\rightarrow$ AA) in the lipoprotein lipase gene. Am. J. Hum. Genet. 47:721-726.

10. Emi, M., A. Hata, M. Robertson, P. H. Iverius, R. Hegele, and J. M. Lalouel. 1990. Lipoprotein lipase deficiency resulting from a nonsense mutation in exon 3 of the lipoprotein lipase gene. Am. J. Hum. Genet. 47:107-111.

11. Hata, A., M. Robertson, M. Emi, and J. M. Lalouel. 1990. Direct detection and automated sequencing of individual alleles after electrophoretic strand separation: identification of a common nonsense mutation in exon 9 of the human lipoprotein lipase gene. Nucleic Acids Res. 18:5407-5411.

12. Henderson, H. H., R. Devlin, J. Peterson, J. D. Brunzell, and M. R. Hayden. 1990. Frameshift mutation in exon 3 of the lipoprotein lipase gene causes a premature stop codon and lipoprotein lipase deficiency. Mol. Biol. Med. 7:511-517.

13. Takagi, A., Y. Ikeda, Z. Tsutsumi, T. Shoji, and A. Yamamoto. 1992. Molecular studies on primary lipoprotein lipase (LPL) deficiency: one base deletion $\left(\mathrm{G}^{916}\right)$ in exon 5 of LPL gene causes no detectable LPL protein due to the absence of LPL transcript. J. Clin. Invest. 89:581-591.

14. Davis, R. C., H. Wong, N. Nikazy, K. Wang, Q. Han, and M. C. Schotz. 1992. Chimeras of hepatic lipase and lipoprotein lipase: domain localization of enzyme-specific properties. J. Biol. Chem. 267:21499-21504.

15. Ma, Y., T. Bruin, S. Tuzgol, B. I. Wilson, G. Roederer, M. S. Liu, J. Davignon, J. J. P. Kastelein, J. D. Brunzell, and M. R. Hayden. 1992. Two naturally occurring mutations at the first and second bases of codon aspartic acid 156 in the proposed catalytic triad of human lipoprotein lipase. J. Biol. Chem. 267:1918-1923.

16. Faustinella, F., A. Chang, J. P. Van Biervliet, M. Rosseneau, N. Vinaimont, L. C. Smith, S. H. Chen, and L. Chan. 1991. Catalytic triad residue mutation (Asp156 $\rightarrow$ Gly) causing familial lipoprotein lipase deficiency. J. Biol. Chem. 266:14418-14424.

17. Derewenda, Z. S., and C. Cambillau. 1991. Effects of gene mutations in lipoprotein and hepatic lipases as interpreted by a molecular model of the pancreatic triglyceride lipase. J. Biol. Chem. 266:23112-23119.

18. Hata, A., D. N. Ridinger, S. C. Sutherland, L. K. Kwong, J. Shuhua, A. Lubbers, B. Guy-Grand, A. Basdevant, P. H. Iverius, D. E. Wilson, et al. 1992. Missense mutations in exon 5 of the human lipoprotein lipase gene: inactivation correlates with loss of dimerization. J. Biol. Chem. 267:20132-20139.

19. Brunzell, D. 1989. Familial lipoprotein lipase deficiency and other causes of the chylomicronemia syndrome. In The Metabolic Basis of Inherited Disease. 6th edition. C. R. Scriver, A. L. Beaudet, W. S. Sly, and D. Valle, editors. McGraw-Hill, Inc., New York. 1165-1180.

20. Wilson, D. E., M. Emi, P. H. Iverius, A. Hata, L. L. Wu, E. Hillas, R. R. Williams, and J. M. Lalouel. 1990. Phenotypic expression of heterozygous lipoprotein lipase deficiency in the extended pedigree of a proband homozygous for a missense mutation. J. Clin. Invest. 86:735-750.

21. Babirak, S. P., P. H. Iverius, W. Y. Fujimoto, and J. D. Brunzell. 1989. The detection of the heterozygote state for lipoprotein lipase deficiency. Arteriosclerosis. 9:326-334.

22. Emi, M., D. E. Wilson, P. H. Iverius, L. Wu, A. Hata, R. Hegele, R. R. 
Williams, and J. M. Lalouel. 1990. Missense mutation (Gly $\rightarrow \mathrm{Glu}_{188}$ ) of human lipoprotein lipase imparting functional deficiency. J. Biol. Chem. 265:59105916.

23. Brunzell, J. D., W. R. Hazzard, A. G. Motulsky, and E. L. Bierman. 1975. Evidence for diabetes mellitus and genetic forms of hypertriglyceridemia as independent entities. Metab. Clin. Exp. 24:1115-1121.

24. Wilson, D. E., and W. V. Brown. 1978. Lipid and lipoprotein abnormalities in diabetes mellitus. Adv. Mod. Nutr. 2 (Part 1):127-186.

25. Iverius, P. H., and A. M. Ostlund-Lindqvist. 1986. Preparation, characterization, and measurement of lipoprotein lipase. Methods Enzymol. 129:691-704.

26. Auwerx, J. H., S. P. Babirak, W. Y. Fujimoto, P. H. Iverius, and J. D. Brunzell. 1989. Defective enzyme protein in lipoprotein lipase deficiency. Eur. J. Clin. Invest. 19:433-437.

27. Shirai, K., and R. L. Jackson. 1982. Lipoprotein lipase-catalyzed hydrolysis of p-nitrophenyl butyrate. J. Biol. Chem. 257:1253-1258.

28. Quinn, D. M., K. Shirai, R. L. Jackson, and J. A. K. Harmony. 1982. Lipoprotein lipase catalyzed hydrolysis of water-soluble $p$-nitrophenyl esters: inhibition by apolipoprotein C-II. Biochemistry. 21:6872-6879.

29. Burdette, R. A., and D. M. Quinn. 1986. Interfacial reaction dynamics and acyl-enzyme mechanism for lipoprotein lipase-catalyzed hydrolysis of lipid p-nitrophenyl esters. J. Biol. Chem. 261:12016-12021.

30. Orita, M., Y. Suzuki, T. Sekiya, and K. Hayashi. 1990. Rapid and sensitive detection of point mutations and DNA polymorphisms using the polymerase chain reaction. Genomics. 5:874-879.

31. Orita, M., T. Sekiya, and K. Hayashi. 1990. DNA sequence polymorphisms in Alu repeats. Genomics. 8:271-278.

32. Selden, R. F., K. Burke-Howie, M. D. Rowe, H. M. Goodman, and D. D. Moore. 1986. Human growth hormone as a reporter gene in regulation studies employing transient gene expression. Mol. Cell. Biol. 6:3173-3179.

33. Goldstein, J. L., H. G. Schrott, W. R. Hazzard, E. L. Bierman, and A. G. Motulsky. 1973. Hyperlipidemia in coronary heart disease. II. Genetic analysis of lipid levels in 176 families and delineation of a new, inherited disorder, combined hyperlipidemia. J. Clin. Invest. 52:1544-1568.

34. Beg, O. U., M. S. Meng, S. I. Skarlatos, L. Previato, J. D. Brunzell, H. B. Brewer, Jr., and S. S. Fojo. 1990. Lipoprotein lipase ${ }_{\text {Bethesda }}$ : a single amino acid substitution (Ala-176 $\rightarrow$ Thr) leads to abnormal heparin binding and loss of enzymatic activity. Proc. Natl. Acad. Sci. USA. 67:3474-3478.

35. Bank, S., I. N. Marks, and A. I. Vinik. 1975. Clinical and hormonal aspects of pancreatic diabetes. Am. J. Gastroenterol. 64:13-22.

36. Kissebah, A. H., S. Alfarsi, D. J. Evans, and P. W. Adams. 1982. Integrated regulation of very low density lipoprotein triglyceride and apolipoprotein B kinetics in non-insulin-dependent diabetes mellitus. Diabetes. 31:217-225.

37. Chait, A., and J. D. Brunzell. 1983. Severe hypertriglyceridemia: role of familial and acquired disorders. Metab. Clin. Exp. 32:209-213.

38. Ishimura-Oka, K., C. F. Semenkovich, F. Faustinella, I. J. Goldberg, N. Schacter, P. Herbert, P. D. Thompson, L. C. Smith, K. Oka, and L. Chan. 1991 Identification of compound heterozygotes for lipoprotein lipase deficiency in three unrelated families. Arterioscler. Thromb. 11:1215a. (Abstr.)

39. Deeb, S. S., M. Reina, J. Peterson, K. Takata, G. Kajiyama, and J. D. Brunzell. 1991. Gene mutations in patients with lipoprotein lipase deficiency. Arterioscler. Thromb. 11:1418a (Abstr.)

40. Sprecher, D. L., J. Kobayashi, M. Rymaszewski, I. J. Goldberg B. V. Harris, P. S. Bellet, D. Ameis, R. L. Yunker, D. M. Black, E. A. Stein, et al. 1992.
$\operatorname{Trp}^{64} \rightarrow$ nonsense mutation in the lipoprotein lipase gene. J. Lipid Res. 33:859866.

41. Winkler, F. K., A. D'Arcy, and W. Hunziker. 1990. Structure of human pancreatic lipase. Nature (Lond.). 343:771-774.

42. Wang, C. S., J. Hartsuck, and W. J. McConathy. 1992. Structure and functional properties of lipoprotein lipase. Biochim. Biophys. Acta. 1123:1-17.

43. Iverius, P. H., and A. M. Östlund-Lindqvist. 1976. Lipoprotein lipase from bovine milk. Isolation procedure, chemical characterization, and molecular weight analysis. J. Biol. Chem. 251:7791-7795.

44. Olivecrona, T., G. Bengtsson, and J. C. Osborne, Jr. 1982. Molecular properties of lipoprotein lipase. Effects of limited trypsin digestion on molecular weight and secondary structure. Eur. J. Biochem. 124:629-633.

45. Osborne, J. C. Jr., G. Bengtsson-Olivecrona, N. S. Lee, and T. Olivecrona. 1985. Studies on inactivation of lipoprotein lipase: role of the dimer to monomer dissociation. Biochemistry. 24:5606-5611.

46. Garfinkel, A. S., E. S. Kempner, O. Ben-Zeev, J. Nikazy, S. J. James, and M. C. Schotz. 1983. Lipoprotein lipase: size of the functional unit determined by radiation inactivation. J. Lipid Res. 24:775-780.

47. Kempner, E. S., J. C. Osborne, L. J. Reynolds, R. A. Deems, and E. A. Dennis. 1991. Analysis of lipases by radiation inactivation. Methods Enzymol. 197:280-288.

48. Ashby, P., A. M. Tolson, and D. S. Robinson. 1978. The heterogeneity of the lipoprotein lipase of rat epididymal adipose tissue. Biochem. J. 171:305-311.

49. Vannier, C., and G. Ailhaud. 1989. Biosynthesis of lipoprotein lipase in cultured mouse adipocytes. II. Processing, subunit assembly, and intracellular transport. J. Biol. Chem. 264:13206-13216.

50. Wong, H., R. C. Davis, J. Nikazy, K. E. Seebart, and M. C. Schotz. 1991 Domain exchange: characterization of a chimeric lipase of hepatic lipase and lipoprotein lipase. Proc. Natl. Acad. Sci. USA. 88:11290-11294.

51. Bengtsson-Olivecrona, G., and T. Olivecrona. 1985. Binding of active and inactive forms of lipoprotein lipase to heparin. Biochem. J. 226:409-413.

52. Augustin, J., H. Freeze, P. Tejada, and W. V. Brown. 1978. A comparison of molecular properties of hepatic triglyceride lipase and lipoprotein lipase from human post-heparin plasma. J. Biol. Chem. 253:2912-2920.

53. Bensadoun, A., C. Ehnholm, D. Steinberg, and W. V. Brown. 1974. Purifcation and characterization of lipoprotein lipase from pig adipose tissue. J. Biol. Chem. 249:2220-2227.

54. Ikeda, Y., A. Takagi, and A. Yamamoto. 1989. Purification and characterization of lipoprotein lipase and hepatic triglyceride lipase from human postheparin plasma: production of monospecific antibody to the individual lipase. Bio chim. Biophys. Acta. 1003:254-269.

55. Shrag, J. D., F. K. Winkler, and M. Cygler. 1992. Pancreatic lipases: evolutionary intermediates in a positional change of catalytic carboxylates? $J$. Biol. Chem. 267:4300-430.

56. Hide, W. A., L. Chan, and W. H. Li. 1992. Structure and evolution of the lipase superfamily. J. Lipid Res. 33:167-178.

57. Paulweber, B., H. Wiebusch, G. Miesenboeck, H. Funke, G. Assman, B. Hoelzl, M. J. Sippl, W. Friedl, J. R. Patsch, and F. Sandhofer. 1991. Molecular basis of lipoprotein lipase deficiency in two Austrian families with type I hyperlipoproteinemia. Atherosclerosis. 86:239-250.

58. The Lipid Research Clinics Population Studies Data Book. 1980. Volume I. The Prevalence Study. U.S. Department of Health and Human Services, Bethesda, MD. NIH Publication No. 80-1527. 